\title{
A Strangulated Meckel's Diverticulum in an Inguinal Hernia: A Case Report and Literature Review
}

\author{
Garrett GRJ Johnson (1D) 1,2 \\ James Holden' \\ Ramzi M Helewa' \\ David Hochman' \\ Eric Hyun' \\ 'Department of Surgery, Section of \\ General Surgery, University of Manitoba, \\ Winnipeg, Manitoba, Canada; ${ }^{2}$ Clinician \\ Investigator Program, University of \\ Manitoba, Winnipeg, Manitoba, Canada
}

\begin{abstract}
Background: Meckel's diverticulum is an embryologic remnant of the vitelline duct, occurring in approximately $2 \%$ of the adult population. A hernia containing a Meckel's diverticulum is called a Littré's hernia and is rarely reported in the medical literature. Clinically, a Littré's hernia is indistinguishable from a hernia containing small bowel and is often discovered incidentally during a repair.

Case Presentation: Herein, we report a rare case of strangulated Littré's hernia in a patient's right groin. The sac contained a long segment of small bowel in addition to a large Meckel's diverticulum. The bowel was irreducible through the groin incision, and a lower midline laparotomy was made. Necrotic bowel including the Meckel's diverticulum was resected. Given the presence of necrotic bowel and potential for infection, the hernia was repaired with a Bassini herniorrhaphy, reinforced with absorbable mesh. The patient recovered uneventfully. Conclusion: Littré's hernia is a rare clinical entity. Treatment is similar to any bowelcontaining hernia. Repair of the hernia defect with permanent mesh should be weighed against the risk of implant infection.
\end{abstract}

Keywords: Meckel's diverticulum, Littré's hernia, inguinal hernia

\section{Introduction}

A Meckel's diverticulum of the gastrointestinal tract is a remnant of the embryologic vitelline duct occurring in approximately $2 \%$ of the population. ${ }^{1}$ It is typically located in the ileum approximately $50 \mathrm{~cm}$ from the ileocecal valve, and remains asymptomatic in $91-96 \%$ of people. ${ }^{1}$ When symptomatic, individuals most commonly experience painless rectal bleeding, bowel obstruction, or inflammation. ${ }^{1}$ A hernia containing a Meckel's diverticulum is termed a Littré's hernia, named after the French physician Alexis Littré, who originally described the condition in the 18th century. ${ }^{2,3}$ Littré's hernia is extremely rare with an unknown incidence. A recent systematic review identified only 53 of these hernias published in the literature, most commonly in the groin $(73 \%) .{ }^{4}$ We present a case of a $39-$ year-old man with a previous laparoscopic left inguinal hernia repair presenting acutely with a strangulated right inguinal hernia containing a long segment of small bowel and a large Meckel's diverticulum. We provide a review of the literature for this rare clinical presentation and discuss appropriate treatment options.

\section{Case Presentation}

A 39-year-old man presented to the emergency department with an 8-hour history of an acutely painful enlarged right hemi-scrotum and obstipation. His medical history includes a previous left inguinal hernia repaired laparoscopically at 
another institution nine years prior. He had noticed an enlarging but easily reducible right groin mass for the past 2 to 3 years, for which he had not sought care. During this current presentation, he appeared in significant discomfort, and diaphoretic. Heart rate was 110 beats per minute but he remained afebrile with normal blood pressure. There was a mass present in the right groin which extended into the right hemi-scrotum measuring approximately $15 \mathrm{~cm}$ in size. The mass was firm, tender, and non-reducible. His scrotum had overlying skin erythema. His abdomen was diffusely tender with mild distension but no peritoneal signs.

A diagnosis of an incarcerated right inguinal hernia with concern for strangulation was established immediately after a physical exam. Further imaging or laboratory evidence was deemed unnecessary based upon his clinical findings and concern for strangulation. Intravenous fluid resuscitation and antibiotics were initiated, and the patient was brought immediately to the operating room for open inguinal hernia repair. A large indirect hernia sac was identified and dissected from the cord structures. The hernia sac was then opened revealing markedly dilated necrotic bowel. A gentle retraction did not result in adequate mobilization of the necrotic bowel to the operative field as the bowel appeared to be fixed in the right groin. Therefore, a lower midline laparotomy was made. The bowel was reduced through the hernia defect and examined through the midline incision. A $20 \mathrm{~cm}$ segment of necrotic bowel was identified, including a large Meckel's diverticulum measuring approximately $15 \mathrm{~cm}$ in length (Figure 1). There was no perforation. A wound protector was inserted (not shown), and a bowel resection of the necrotic segment and a primary stapled side-to-side anastomosis was performed. The hernia was repaired using a Bassini technique, reinforced with an overlying absorbable Vicryl mesh (Ethicon Inc., Somerville, New Jersey, United States). The midline laparotomy was closed primarily. The patient had a rapid return of bowel function and was discharged from the hospital on post-operative day 2. The patient was seen in follow-up at 6 weeks and remained well. The pathology report confirmed the presence of a large Meckel's diverticulum containing pancreatic tissue.

\section{Discussion}

Littré's hernia is a rare presentation of a Meckel's diverticulum. While this clinical entity was first described in a 3-patient case series in $1700,{ }^{3}$ very few subsequent

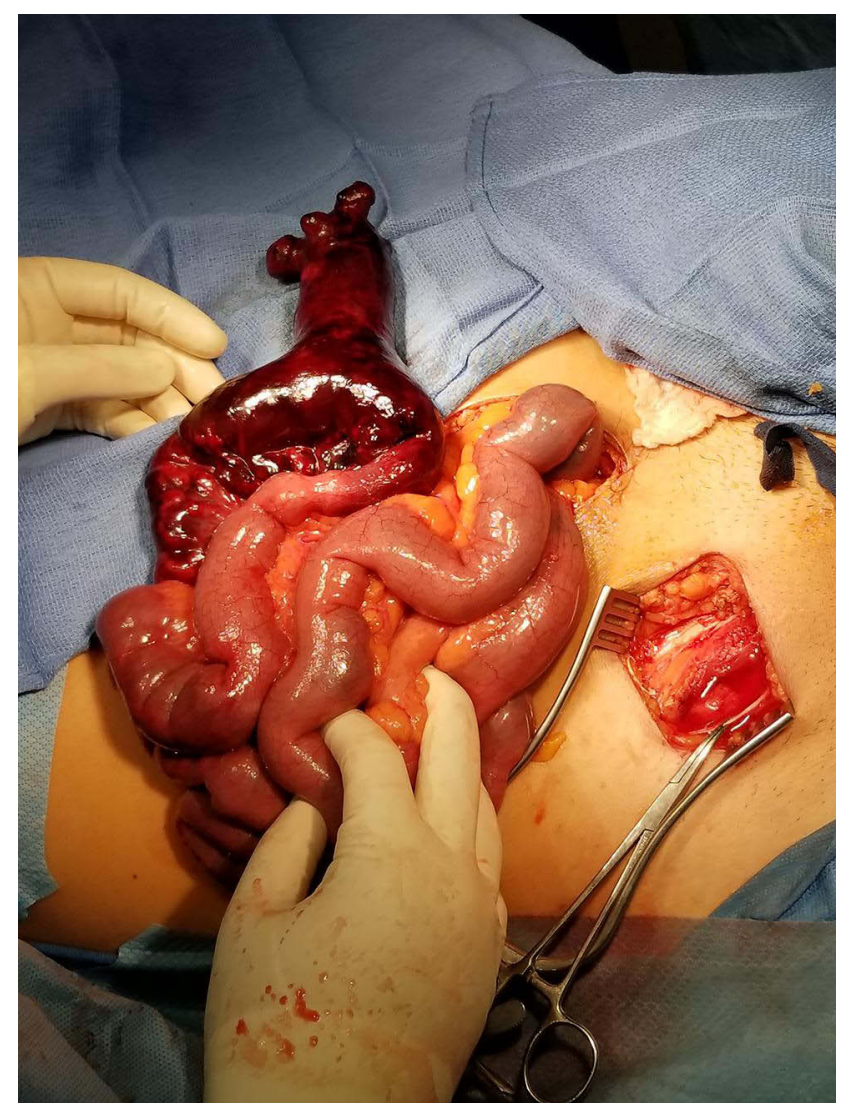

Figure I Intraoperative image of Meckel's diverticulum and non-viable bowel released from the hernia sac and extricated through midline laparotomy prior to resection.

reports have been documented in the literature. ${ }^{4}$ Some contend that the original description by Littré was actually a misidentification of what was later to be classified as a Richter's hernia. ${ }^{2}$ These two hernia subtypes differ in that a Richter's hernia contains a traction diverticulum formed by the protrusion of part of the intestine's antimesenteric border through a defect in the abdominal wall, whereas a Littré's hernia contains a Meckel's diverticulum, formed from a failure of agenesis of the embryologic remnant vitelline duct. ${ }^{5}$

Littré's hernia has been classified into two distinct subtypes. A “true" Littré's hernia, which is more common, contains the Meckel's diverticulum alone and can be most easily confused for a Richter's hernia. A “mixed” Littré's hernia contains a segment of small bowel in addition to a Meckel's diverticulum and is less commonly reported. ${ }^{4}$ This current case describes that of a mixed Littré's hernia, presenting with obstruction and acute bowel necrosis. As in the current case, Littré's hernia is most commonly diagnosed incidentally during the operative repair of an inguinal hernia. Previously, relative resistance to ischemia 
in the Meckel's diverticulum was proposed in comparison to small bowel strangulated hernias. ${ }^{6,7}$ By contrast, the current case reports irreversible bowel ischemia that had progressed rapidly within 8 hours of symptom onset.

Previously, 53 cases of Littré's hernia have been reported in the literature, including 18 inguinal hernias, 24 cases of bowel strangulation, and 18 cases of bowel obstruction. ${ }^{4}$ To our knowledge, this is the first case of inguinal "mixed" Littré's hernia reported in the literature leading to bowel infarction and obstruction. In such a circumstance, clinical decision-making is similar to any bowel-containing strangulated inguinal hernia. In this case, resection was required due to intestinal necrosis, including resection of the diverticulum, to avoid perforation and death. Moreover, in the current case, this patient had a "giant" Meckel's diverticulum as it was greater than $5 \mathrm{~cm}$ in length. Giant Meckel's have been previously shown to be prone causing to symptomatology, thus a further indication for resection. ${ }^{8}$

A Littré's hernia in the context of viable bowel represents another interesting clinical scenario for which a variety of treatment options are available, with various management options reported in the literature. It is generally recommended that symptomatic Meckel's diverticula should be surgically resected to alleviate symptoms and prevent complications. ${ }^{9}$ Management of asymptomatic Meckel's diverticula identified incidentally is more controversial, ${ }^{10}$ with some advocating prophylactic resection, ${ }^{11-13}$ and others encouraging expectant management. ${ }^{14-19}$ The situation of an incidentally detected Littré's hernia during a planned repair of an inguinal hernia represents a more challenging distinct clinical entity. An argument can be made that the hernia itself accounts for the symptomatology, rather than the Meckel's diverticulum, which has otherwise remained asymptomatic for the patient. Furthermore, the resection required for treatment of the Meckel's transforms a "clean" operation into a "clean-contaminated" procedure, increasing the risk of perioperative complication. For inguinal hernia repairs, surgeons must therefore carefully weigh the risks of mesh infection against the risks of hernia recurrence in addition to the risks associated with the Meckel's diverticulum.

In a prior systematic review, the lifetime rate of Meckel's diverticula causing symptoms is only $4-9 \%{ }^{1}$ This rate is likely lower in middle-aged adult patients without symptomatology to date, such as in the case presented. A resection essentially eliminates this risk; however, it potentially adds other surgical site infection risks or operative complications. ${ }^{9}$ The risk of an inguinal hernia mesh infection following elective surgery is less than $1 \%{ }^{20}$ Inguinal hernias electively repaired with mesh have a recurrence rate $1-3 \%$ over 5 years. ${ }^{21}$ In clean/contaminated operations, infection risk theoretically increases, although this relative risk increase was not observed in multiple large studies. ${ }^{22}$ When this does occur, mesh infection is a devastating complication often necessitating prolonged intravenous antibiotics or mesh removal. An alternative commonly used in contaminated or dirty fields is to perform a tissue-only repair, such as a Bassini or McVay repair; however, these repairs have generally unacceptable recurrence rates, as high as $15 \%$ in emergency settings. $^{21}$ In the present case, due to bowel necrosis and heightened risk of surgical site infection, a Bassini repair was performed, and a rapidly absorbable Vicryl mesh was placed for added stability. Although the benefit of adding absorbable mesh to this tissue repair is poorly studied, the risks of graft infection of absorbable mesh in high-risk surgical fields are low. ${ }^{20}$ Alternatively, the use of an absorbable biologic mesh can be considered however, but this comes at markedly increased cost, although it may decrease recurrence risk. ${ }^{23}$ In the present case, there was thought to be a minimal added risk from the placement of an absorbable mesh, with theoretical benefits for added stability. The defect was quite large, and we felt the mesh would add additional strength. In a small case series, the addition of a mesh to a Bassini repair decreased the risk of recurrence compared to mesh alone. $^{24}$

Given the rarity of Littré's hernia presentations, it is unlikely that randomized prospective evidence will ever inform treatment decision-making for this rare clinical entity. Extrapolation of data from similar clinical entities is prudent. The World Society of Emergency Surgery (WSES) 2017 emergency hernia repair guidelines recommend permanent mesh placement in a "clean-contaminated" surgical field due to low risk of infection and prevention of recurrence. $^{22}$ Therefore, if an incidental Meckel's is resected at inguinal hernia repair, a permanent mesh can likely be placed safely. This position is also supported by data extrapolated from a recent systematic review of treatment for the more common Amyand's hernia (inguinal hernia containing the appendix). ${ }^{25}$ By contrast, for contaminated or dirty surgery following strangulated inguinal hernia with necrosis, tissue-only repair or biologic mesh placement should be considered in accordance with WSES guidelines. $^{22}$ In the present case, there was no fecal 
contamination, therefore a prolene mesh could be considered when strictly following these guidelines. The decision to forgo permanent mesh placement in favor of a tissue repair reinforced with absorbable mesh was made due to the significant bowel necrosis and the patient's physiologic signs of sepsis.

\section{Conclusion}

Herein we present a case of a mixed Littré's inguinal hernia involving a long segment of necrotic small bowel and a large Meckel's diverticulum. Littré's hernia is rare, however treatment is analogous to any bowel-containing hernia. Definitive management includes surgical resection of the diverticulum followed by herniorrhaphy. The placement of permanent mesh should be carefully weighed against the risks of implant infection.

\section{Abbreviations}

WSES, World Society of Emergency Surgery.

\section{Declarations}

This work is original and is not under consideration elsewhere.

\section{Meetings}

This work has not been presented at any scientific meetings.

\section{Ethics Approval and Informed Consent for Publication}

Informed consent for publication of the patient's medical details and photographs was obtained from the patient prior to publication. Institutional approval was obtained from the University of Manitoba's Health Research Ethics Board.

\section{Author Contributions}

All authors contributed to data analysis, drafting or revising the article, gave final approval of the version to be published, agreed to the submitted journal, and agree to be accountable for all aspects of the work.

\section{Funding}

There was no specific funding for this research.

\section{Disclosure}

The authors declare that they have no conflicts of interest for this work.

\section{References}

1. Hansen C-C, Søreide K. Systematic review of epidemiology, presentation, and management of Meckel's diverticulum in the 21st century. Medicine. 2018;97(35):e12154. doi:10.1097/MD.00000000 00012154

2. Weinstein BM. Strangulated littre's femoral hernia with spontaneous fecal fistula: a case report with a review of the literature. Ann Surg. 1938;108(6):1076-1082. doi:10.1097/00000658193812000-00009

3. Littré A. Observation sur une nouvelle espèce de hernie. [Observation on a new species of hernia]. Mem Math Phys Acad Sci. 2006;1700:300-310. Available from: https://hal. archives-ouvertes.fr/ads-00104348/document. Accessed August 31, 2021.

4. Schizas D, Katsaros I, Tsapralis D, et al. Littre's hernia: a systematic review of the literature. Hernia. 2019;23(1):125-130. doi:10.1007/ s10029-018-1867-0

5. Skandalakis PN, Zoras O, Skandalakis JE, Mirilas P. Littre hernia: surgical anatomy, embryology, and technique of repair. Am Surg. 2006;72(3):238-243. doi:10.1177/000313480607200309

6. Mirza MS. Incarcerated littre's femoral hernia: case report and review of the literature. J Ayub Med Coll Abbottabad. 2007;19(2):60-61.

7. Horkoff MJ, Smyth NGC, Hunter JM. A large incarcerated Meckel's diverticulum in an inguinal hernia. Int J Surg Case Rep. 2014;5 (12):899-901. doi:10.1016/j.ijscr.2014.09.036

8. Farooq M, Rajesh A. Giant Meckel's diverticulum compressing root of mesentery - a rare cause of ileal gangrene - case report and review of literature. Int J Surg Case Rep. 2017;38:53-56. doi:10.1016/j. ijscr.2017.06.063

9. Sagar J, Kumar V, Shah DK. Meckel's diverticulum: a systematic review. J R Soc Med. 2006;99(10):501-505. doi:10.1258/jrsm.99.10.501

10. Park JJ, Wolff BG, Tollefson MK, Walsh EE, Larson DR. Meckel diverticulum: the Mayo Clinic experience with 1476 patients (19502002). Ann Surg. 2005;241(3):529-533. doi:10.1097/01.sla.000015 4270.14308.5f

11. Arnold JF, Pellicane JV. Meckel's diverticulum: a ten-year experience. Am Surg. 1997;63(4):354-355.

12. Bani-Hani KE, Shatnawi NJ. Meckel's diverticulum: comparison of incidental and symptomatic cases. World J Surg. 2004;28(9): 917-920. doi:10.1007/s00268-004-7512-3

13. Robijn J, Sebrechts E, Miserez M. Management of incidentally found Meckel's diverticulum a new approach: resection based on a risk score. Acta Chir Belg. 2006;106(4):467-470. doi:10.1080/00015458. 2006.11679933

14. Soltero MJ, Bill AH. The natural history of Meckel's diverticulum and its relation to incidental removal. A study of 202 cases of diseased Meckel's diverticulum found in King County, Washington, over a fifteen year period. Am J Surg. 1976;132(2):168-173. doi:10.1016/0002-9610(76)90043-x

15. Ueberrueck T, Meyer L, Koch A, Hinkel M, Kube R, Gastinger I. The significance of Meckel's diverticulum in appendicitis-a retrospective analysis of 233 cases. World J Surg. 2005;29(4):455-458. doi:10.1007/s00268-004-7615-x

16. Zani A, Eaton S, Rees CM, Pierro A. Incidentally detected Meckel diverticulum: to resect or not to resect? Ann Surg. 2008;247 (2):276-281. doi:10.1097/SLA.0b013e31815aaaf8

17. Stone PA, Hofeldt MJ, Campbell JE, Vedula G, DeLuca JA, Flaherty SK. Meckel diverticulum: ten-year experience in adults. South Med J. 2004;97(11):1038-1041. doi:10.1097/01.SMJ.0000125222.90696.03

18. Kashi SH, Lodge JP. Meckel's diverticulum: a continuing dilemma? J R Coll Surg Edinb. 1995;40(6):392-394.

19. Peoples JB, Lichtenberger EJ, Dunn MM. Incidental Meckel's diverticulectomy in adults. Surgery. 1995;118(4):649-652. doi:10.1016/ s0039-6060(05)80031-5 
20. Orelio CC, Hessen C, Sanchez-Manuel FJ, Aufenacker TJ, Scholten RJ. Antibiotic prophylaxis for prevention of postoperative wound infection in adults undergoing open elective inguinal or femoral hernia repair. Cochrane Database Syst Rev. 2020;4. doi:10.1002/14651858. CD003769.pub5

21. Lockhart K, Dunn D, Teo S, et al. Mesh versus non-mesh for inguinal and femoral hernia repair. Cochrane Database Syst Rev. 2018;9(9): CD011517. doi:10.1002/14651858.CD011517.pub2

22. Birindelli A, Sartelli M, Di Saverio S, et al. 2017 update of the WSES guidelines for emergency repair of complicated abdominal wall hernias. World J Emerg Surg. 2017;12(1):37. doi:10.1186/ s13017-017-0149-y
23. Öberg S, Andresen K, Rosenberg J. Absorbable meshes in inguinal hernia surgery: a systematic review and meta-analysis. Surg Innov. 2017;24(3):289-298. doi:10.1177/1553350617697849

24. Patil SM, Gurujala A, Kumar A, Kumar KS, Mithun G. Lichtenstein mesh repair (LMR) v/s modified Bassini's repair (MBR) + Lichtenstein mesh repair of direct inguinal hernias in rural population - a comparative study. J Clin Diagn Res. 2016;10(2):PC12PC15.

25. Manatakis DK, Tasis N, Antonopoulou MI, et al. Revisiting amyand's hernia: a 20-year systematic review. World J Surg. 2021;45:1763-1770. doi:10.1007/s00268-021-05983-y

\section{Publish your work in this journal}

The International Medical Case Reports Journal is an international, peer-reviewed open-access journal publishing original case reports from all medical specialties. Previously unpublished medical posters are also accepted relating to any area of clinical or preclinica science. Submissions should not normally exceed 2,000 words or 4 published pages including figures, diagrams and references. The manuscript management system is completely online and includes a very quick and fair peer-review system, which is all easy to use. Visit http://www.dovepress.com/testimonials.php to read real quotes from published authors. 